Covered in: Web of Sciences (WOS); EBSCO; ERIH+; Google Scholar; Index Copernicus; Ideas RePeC; Econpapers; Socionet; CEEOL; Ulrich ProQuest; Cabell, Journalseek; Scipio; Philpapers; SHERPA/RoMEO repositories; KVK; WorldCat; CrossRef; CrossCheck

2018, Volume 9, Issue 1, pages: 109-128 | doi: https://doi.org/10.18662/po/08

\section{A Philosophical Approach of the Modernization Process of Russian Economy and Economic Institutions}

\author{
Alexandra Grigorievna \\ POLYAKOVA ${ }^{1}$, \\ Julia Nikolaevna \\ NESTERENKO ${ }^{2}$, \\ Elena Albertovna \\ SVERDLIKOVA $^{3}$
}

${ }^{1}$ Industrial University of Tyumen, Financial University under the

Government of the Russian

Federation, agpolyakova@mail.ru

Corresponding author

${ }^{2}$ Moscow State Humanities and

Economics University, Russian

Federation, julia-

nesterenko@mail.ru

${ }^{3}$ Lomonosov Moscow State

University, Russian Federation, elena.sverdlikova@gmail.com
Abstract: The article deals with the specific features of functioning and evolution mechanisms of institutional traps as objects of state intervention during the institutional reforms, thus deals with the following hypothesis: there exists a uniform country-specific pattern of institutional traps emergence during economic modernization. Without management of institutions it is not possible to provide realization of an optimal scenario of state development. The spread of positive institutional practices and successful experience of institutional reforms may be considered as a tool of social state development. However, there are situations when newly created institutions fail the task but instead of dying seek to implement old practices, transforming into institutional traps, i.e. stable self-sustainable norms dissonant with aims of social development. Institutional traps, entailing the experience of economic agents' sustainable interaction, derive not only negative effects, but also are considered by the science to be sustainable samples for modelling in order to increase the efficiency of particular institutional interaction areas. The emergence of institutional traps in a certain field of activity has several associated effects: the existence of inefficient institutions can lead to a multiplicative effect and generate "institutions for their own sake", and also to form a supporting infrastructure. Thus, a specific servicing subsystem appears; imposing greater restrictions in an inefficient institution leads to a greater degree of strengthening the servicing subsystem, contributing to the expansion of the informal or shadow sectors. The present sophistication of economic activities causes modification of institutional traps and their management basics. This brings the authors to explore not only the essential aspects of institutional traps, but also the specifics of their transformation. It was discovered that the substantial role in eliminating those traps is prescribed to control mechanisms that appear to be the complex of instrumentally mediated stimulating or restrictive reactions (and diagnostics tools for them as well) to deviation of an institute from pre-assigned behaviour patterns.

Keywords: Institutional theory, institutional reforms, institutional trap, state administration, development institutions.

How to cite: Polyakova, A.G., Nesterenko, J.N., \& Sverdlikova, E.A. (2018). A Philosophical Approach of the Modernization Process of Russian Economy and Economic Institutions. Postmodern Openings, 9(1), 109128. https://doi.org/10.18662/po/08 


\section{Introduction}

The well-coordinated work of institutions and the effectiveness of institutional reforms is the key to successful social and economic development. The multivariate perception of reality generates plurality in interpreting the economic behavior of individuals, as well as the difference in viewpoints regarding the search for solutions to scientific problems. The above-mentioned issues determine the methodological shift from neoclassical theories towards institutional theory. It should be noted that the projection of changes in economic activity is manifested primarily in institutions, as they have the property of adaptability resulting from their ability to respond quickly to changes in the environment that are recorded by a wide range of measurements.

In some cases, specific problems appear in the institutional framework, which are manifested in the lack of effective mechanisms of the main actors' economic interests harmonization and in presence of a set of institutionalized contradictions and traps.

An institutional trap represents stable self-sustaining norm that is dissonant with goals of social development. Research of institutional traps is of special interest because they can act as patterns for modeling stable structures (if the fact of their negative impact on the parameters of socioeconomic development is rejected), since they have well distinguishable properties and characteristics (sustainability, connectedness, selfreproduction, etc.), which are relevant from the research point of view. Mentioned properties define their viability, mode of functioning and evolution mechanisms, which have to be considered in decision making procedures concerning institutional construction and reform.

The paper is aimed to verify the following hypothesis: there exists a uniform country-specific pattern of institutional traps emergence during economic modernization. To do that we look into the nature of institutional traps' phenomenon to determine their causes and facilitators and to distinguish between several other institutional malpractices. Further we summarize institutional traps' properties to set up targets of traps-handling process and its specific features. Deeper survey of theoretic background and empiric retrospective provided a variation of possible paths of institutional traps' evolution that end up in two general scenarios of mutual support or elimination. That allows to set benchmarks and milestones for any trap existing or possibly forthcoming, which is a key to unification. Standing on a 
positive side of the research hypothesis we conclude with policy implications considering traps handling and institutional reform guidelines.

\section{Nature of institutional traps}

Taken in retrospective, the concept of a "trap" in economic literature (political economy) was proposed by J.M. Keynes who used it to describe a situation when the additional money supply to an economy doesn't result in a decrease of interest rates. Further on, the concept of a "trap" may be found in papers of J. Hicks and E. Hansen regarding the dynamics of investment. Significant progress on this issue was contributed by $\mathrm{D}$. North, who, in fact, introduced the term "trap" to describe the effect of "blocking" as a situation in which a government decision once made is difficult to revoke.

In the Russian science the earliest and broadly accepted interpretation of an institutional trap is that of V. Polterovich, who defined it as ineffective sustainable norm (Polterovich, 1999) and actually was the first to describe their essence in the contemporary Russian science.

The dispute concerning the institutional traps understanding is related to their identification criteria. In general, institutional traps are considered as actors' response to the single or longitudinal transformation of the environment, both evolutionary and reformist. The latter interpretation of institutional traps correlates with the formation of atypical, for a given institution, patterns of behavior of intra-institutional interaction agents (Dollar, 2016). Over time, these behavioral models get widely spread because they allow agents to maximize the whole set of benefits from the realization of their interests under the new conditions.

The most often mentioned example of an institutional trap in scientific discourse is the experience of enterprises in adapting to changes in taxation. What is more, this experience cannot be described as exclusively Russian since all businesses regardless of their jurisdiction tend to rationalize their costs from the standpoint of individually decided criteria, which are identical under given economic circumstances. In this regard, practices of barter, IOUs, non-transparent, offshore and other schemes of financial interaction between economic agents can rightly be attributed to benchmark patterns of adaptive behavior. Their further in-depth analysis provides a rational explanation for the various macroeconomic effects described, for example, by the Laffer curve, when increase in the tax burden does not lead to an increase in budget revenues, and, after a certain limit, ensures their reduction. Notably, Williams and Horodnic (2016) explore the case of Great 
Britain to find and explain the strong correlation between "the degree of institutional asymmetry (measured by tax morale) and participation in the informal economy". They conclude that the lower is the tax morale, the greater is the propensity to participate in the informal economy. South Asian experience is also widely discussed in exemplifying institutional traps and failures due to the reasons analyzed in Sultan and Washbrook (2017), adding up specific features of mentality and lack of secularisation.

Nevertheless, there is a reason to disagree with the fact that an institutional trap always indicates failure or inefficiency of a formal institution. It is quite possible that the actual way of organizing interaction of economic actors should be considered as a means of improvement of some formal institution, which is a priori less adaptive and inert. If this is the case, a trap can be described as a roadmap for liberalization and improving the effectiveness of a certain area of institutional interaction.

\section{Role and properties of institutional traps}

In the short term, institutional traps can mitigate the consequences and level out the gaps that arise during reforms. A classic, textbook example is the introduction of barter in early 1990s in Russia, when transition to market had place. But in the long run, acquiring more sustainable properties, an institutional trap begins to contradict the trajectory of socio-economic development. Similar way pattern of a trap is discovered and described in Kolmakov and Polyakova (2017) with respect to temporary shifts of health expenditure from public to private sector that took place in the mid 90-s and became permanent afterwards indicating explicit problem of social insurance malfunction. More evidence of the liberal reforms' heritage in institutional traps found in Yekimova, Savelyeva, and Tsalo (2016), where the Russian regions' consumer prices were proved to be strongly interlinked with the global market conjuncture.

Institutional traps, as follows from Draskovic, Popov, and Peleckis (2017), can be explained by the reaction of economic system to the "cosmetic" change which is basically intended to keep the system unchanged as long as it is possible: "the deficit of real institutional changes ... and their substitutions by the various anti-developmental institutional imitations..., which had anti-institutional and anti-development character". Even though some of the changes that took place in Russia were intended to achieve positive outcomes, they lacked either meaningfulness, or rationality, or necessity, as Kremser (2016) denotes them, or all together. A trap was the most probable result then, thus Russia and several other post-soviet 
economies had much in common on their way of social, economic and institutional transformation, as described in Tridico (2011) or in Frunza (2011).

The sustainability of institutional traps is conditioned by high degree of their embeddedness in the systemic interrelations. Due to the high level of a trap's inter-institutional relatedness, the reform of the socio-economic system, carried out regardless of their interconnection, will not have any significantly progress. Reforming an institute while refraining from analysis of institutional traps' impact (as well as its entire environment) generates an imbalance of rules within institutional environment; such a miscoordination eventually leads to violation of institutional complimentary.

Sustainability gives rise to another important property of institutional traps, which is self-reproduction. An institutional trap is an instrument to achieve institutional balance and equilibrium, a conductor of impulses between institutions. The aggregate of interactions of various factors appears in an institutional trap as a sustainable norm which ensures stabilization in a market economy and coordination between institutions, and, consequently, is constantly reproduced in the process of economic activity. Proceeding from the property of self-reproduction and the principles of evolutionary dynamics, institutions' reform and roll-back to the initial rules do not result into automatic institutional trap elimination.

Institutional traps can appear in the absence of demanded institutions, showing the property of substitution. By its nature, substitution is a property based on demonstration of the institutional mechanism's functioning results. An institutional trap may be a result of deliberate actions, but, as a rule, the substitutes are the result of uncontrolled process when, because of unintended actions, practices are built up that contradic to long-term development goals.

\section{Evolution of institutional traps}

Changes in socio-economic system result in new institutions that appear holding new forms and attributes. If an institution is created artificially, it is obvious that it purpose is to resolve quite definite socioeconomic issues, even if the latter, in their turn, are destructive for the socioeconomic system as a whole. In other words, for example, the establishment of a fund can be of a greater public significance, providing social guarantees and fulfilling needs of vulnerable groups of people. However, the same fund is an instrument of capital outflow, which interrupts its circulation and contradicts some evolutionary parameters of socio-economic system 
development. On the contrary, those institutions which appear and develop evolutionary are subject to totally different selection factors, do not contradict their environment, but rather, organically fit into it. With the natural selection of institutions, the important attributes of socio-economic system are being improved.

The solution of a number of social issues, just as the very fact of a state existence, is not a naturally incorporated parameter and does not appear in the explicit form in the nature of socio-economic systems initially. In this regard, position of A. Marshall (1920) should be noted, according to which, although institutional forms can be changed easily, yet to be sustainable they must conform properly with an individual: they will not remain stable if they change much more quickly than an individual does. Accordingly, nearly all regulators used, are artificial to the system. Some of them may contradict evolutionary trends of its (system) development, while the other, on the contrary, contribute those trends. Along with this, the very nature of institutions is a proof of their connection with a strive to resolve imperatives arising during social evolution.

Institutions carry material for selection. Transforming in a natural way, they entail new forms of socio-economic systems arising. For comparison, we should note that artificial transformations contribute to the emergence of new varieties of socio-economic systems within an existing form. Thus, if artificial selection of institutions takes place, their development follows the prescribed criteria and heads to the direction that is necessary for the society, even though the criteria themselves may be destructive for the system.

The natural selection is historically built into socio-economic systems and is an integral mechanism of their development. Comparing the role of artificial and natural selection of institutions we can conclude that artificial selection results into the types of socio-economic systems that are the most adequate to the needs dictated by an authority, while natural selection entails development of such a system that best corresponds with its environment.

With time, the growth of public demand dictates more and more new requests, which increases the regulative role of the state and, consequently, the role of natural selection becomes less and less important. The growth of competition entails the search for competitive advantages, which shift parameters of socio-economic development to a fundamentally new level. The choice of priorities and leadership factors may be extremely wide, and development institution will conform to the wanted trend. For instance, in a region they can vary from solving the task of raising the means 
of production or infrastructure development to facilitating the increase of the region's comfort for running business or living.

It's clearly obvious that the modern circumstances demand to apply nonstandard approaches to realization of regional management, target it to deal with fundamentally new tasks. Such intentions are not only justified but, as a matter of fact, inevitable. Competition getting more tense requires regions to catch up with the neighboring territories and with the global actors as well. Multilevel competition, supported by globalization leaves no choice to regional economic agents. They are forced to keep pace with existing trends and develop competitive specialization, which, in turn, leads to further degeneration of institutions' natural selection and to intensification of an artificial mode, capable of creating institutions that support regional competitive advantages. That is where we witness the main contradiction. On the one hand, artificially made institutions can develop competitive specialization of a region, but, on the other hand, are much likely not to act synchronously with the environment. Thus, they can will be effective according to one criterion (e.g. factor of competitive specialization) but will be completely or partially unviable when different criteria are given (from the point of view of adequacy to evolutionary properties of the system).

There are situations when newly created institutions don't resolve the proposed tasks but, instead of dying, tend to replicate old practices. We have to agree that quite inefficient institutions can function for a long time, inertially following a previously constructed development trajectory. As a rule, the reason for such a behavior is the conflict between old and new attitudes due to the different vectors of goals and tasks attributable to a separate reform. As a result of such conflict, participants tend to choose the most preferable and the least risky practice, which is usually the previously acting one.

Thus, for example, in socio-economic system one can observe a situation when institutions that implement inefficient practices will be extremely viable, and vice versa. For that matter, the failure of institutions' natural selection mechanism may determine the very existence of institutional traps.

Institutional traps are subject to changes due to the complexity of economic activity. As shown by K. Yanovskiy and S. Shulgin who analyzed 1820-2000 worldwide data series, "democracies demonstrate the ability to export capital, knowledge and, in rare cases (in the presence of political will), even effective institutions, stimulating the growth of the entire world economy" (Yanovskiy \& Shulgin, 2008). The process of institutional reforms 
may get more complicated because of institutional traps' interaction and overlap that have three possible patterns:

- neutral, suggesting no interaction;

- negative influence, when one trap exists and evolves consuming the other one's resources;

- conditionally positive influence, suggesting that the evolution of one trap entails the progression of another.

The third option is conditional because its result is not rigid in the long run since a trap's influence on economic and/or social development is still negative and the postponed damage can get much more significant because of that overlap.

Forms of interaction of the traps of conditionally positive nature also show diversity and in a systematized form may be presented as follows:

- Mutually advantageous ties, when the interaction acts as a condition of the other party's existence. Advantages derived from this interaction may include, on the one hand, gain of economic resources, access to the sources of benefits, and on the other hand, evasion from the rule of law or liability for illegal access to these benefits and so on;

- Ties which are only beneficial for one trap, but which negatively affect another. In such a case, traps can be multilevel and characterized by a completely different scale. These ties suggest that norms and rules that have developed within the traps coexist over long period of time in a form of antagonistic relations when one trap acts as a provider of resources or a development environment;

- Ties, expedient (or, otherwise, carrying a negative meaning) for one trap, but indifferent for another. As a rule, such kind of relations is typical for traps of different levels;

- Ties, when one trap becomes (or initially is) a part of another. If that is the case, the formation of the trap network is possible, synergetic effects of which may cause destructive consequences.

\section{Handling institutional traps}

Trap management involves their analysis and identification of the causes of their occurrence. As an instrument for communication, traps appear in the situations when communicative disruptions have place, such as:

- Spatial, including horizontal, which take place due to inconsistency of interests of different groups of economic actors, and vertical, happening because of mismatch of interests of groups of different levels; 
- Temporary, arising as a result of mismatch of short-term and longterm group interests.

The state policy is a reflection of interests of society exclusively in a space of social consensus. In this case, coordination of interests results in the emergence of the relevant institutions, called upon to ensure those interests. In case of interests' mismatch, when consensus between authorities and society is violated, there are processes to generate subjectively constructive concepts, which are similar in nature but different in content, aiming to restore the balance of interests by means of the respective party. In such cases, we can assume the emergence of an institutional trap, the effect of which, ultimately, levels-off the degree of interests' mismatch and forms an alternative symbiotic institution that would not appear in any other circumstances (see Fig. 1).

Interests

mismatch, generation of

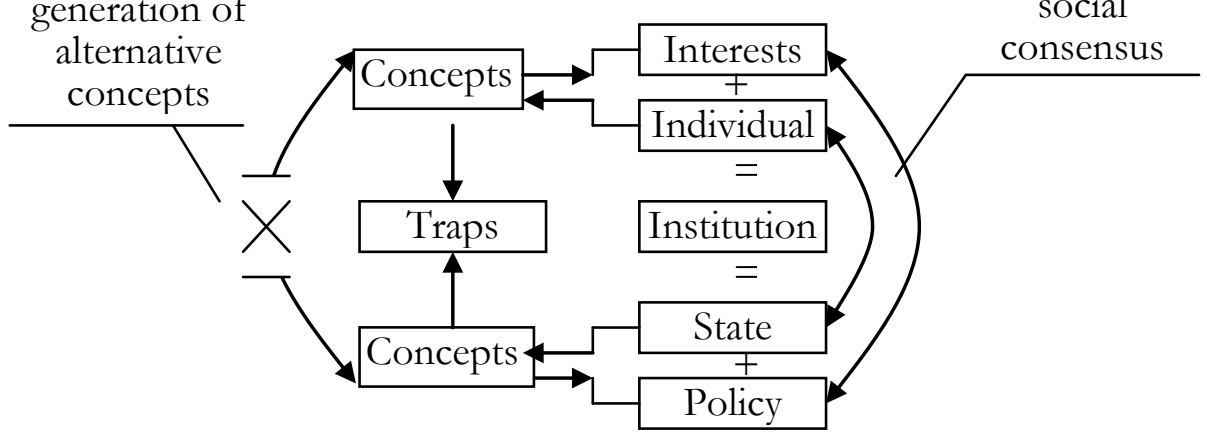

Figure 1 Algorithm for the emergence of institutional traps

The larger is the scale of institution, both in terms of the numbers of groups involved, and in terms of its capacity (economic, corruption, etc.), the more likely is the emergence of duplicative and complementary institutions. Similar patterns are also appropriate for decreasing scales, i.e. for geographically or socially compact institutional entities.

Arise of institutional traps in a certain field has several side-effects, the lifetime of which is closely related to institutional contradiction generating them. One of the most striking effects is the formation of a whole layer of "institutions for the sake of institutions", designed, in general, to overcome or to smooth the difficulties of transition period. Emerging as such, they place restructuring and defragmenting impact on the pattern of institutional interactions, being reliably embedded into the economic mechanisms, resulting in an increase of transaction costs. E.g., changes in tax legislation provoke the emergence of counteracting schemes, based on the true variety of 
institutions, such as offshore banks and enterprises, artificial acquisition of privileges and preferences provided for by the law, etc.

A demonstrative example of an institutional trap in Russian social sphere, though, not endemic, is the law on public procurement (Federal Law No. 94-FZ). The achievement of its goals caused the number of contradictions, finally settled down by new institutions, which would not emerge otherwise, such as: mediation in the placement of orders, procurement brokers, budgeting consultants, overspending, corruption schemes, etc. In a similar manner there are changes in the legislation on nonprofit organizations that limit the possibilities of, beside others, social organizations to raise private funding: the emergence of various kinds of schemes to escape from that law jurisdiction eloquently demonstrates the phenomenon discussed.

An exceptional example from the social sphere is demonstrated by an institution of "maternity capital", the lack of effective use of which creates artificial fluctuations in demand in related spheres, placing additional duties on existing institutions, such as banks or intermediaries in the real estate market. Thus, the established practice indicates that the recipients of maternity capital are looking for legal ways to take use of it before it will be devaluated due to inflation and other factors. The goal is achieved by getting mortgages in banks, refinanced in the future by means of maternity capital, and at the heart of these deals often lie real estate purchase contracts between affiliated individuals who hire real estate agents that already have signs of appropriate specialization.

Thus, existence of inefficient institutions may result in multiplier effect and generate "institutions for their own sake" accompanied by supporting infrastructure. Finally, we face the servicing subsystem for both efficient and inefficient institutions. Imposing greater restrictions for the latter one usually increases the viability of the servicing subsystem thus facilitating the expansion of the informal or shadow sectors. In general, the negative effects of institutionalization appear in development of informal economic relations between economic agents intended to statutory rules and regulations misconduct.

\section{Preventing and neutralizing the negative effects of institutional traps}

Neutralization of a trap's effect, its elimination or prevention presume quite different actions. Escape from an institutional trap appears to be much more serious process then it may be thought at a glance. It requires 
measures concerning transition of the servicing subsystem to other segments and providing it with an alternative donor, which requires significant expenditure and, at the same time, flexibility in terms of decision-making process.

The break of informal ties, which set up within institutional traps, will be successful if alternative options for all process participants are provided. Those options must be equivalent or comparable with the source of income elimination. For that matter, mechanism of compensatory deals may be used to overcome highly probable resistance of the establishment, whose powers may extend to the field, where those traps are localized.

In line with Caballero and Soto-Onate (2015) who argue that "understanding the complexity of institutional change is a necessary step in gaining deeper knowledge of economic performance over time", we conclude that underestimation of compensatory mechanisms' importance should not take place while planning an institutional change because otherwise existing institutions will face significant risk of destabilization. Important as well is the point of Deroy and Clegg (2015) who argue that a planned institutional change is necessary at least to avoid eventual change that could turn unpredicted.

One of the options to avoid institutional traps is the reasonable restriction of the lifetime for transition institutions created during reforms. In this case the probability that the motive of economic expediency by numerous third-party agents will be rethought increases significantly, which, eventually, will allow to exclude their undermining the influence on the final goal of the newly introduced institution exploitation. Nevertheless, there is a consensus about the necessity and inevitability of institutional units to foster and facilitate economic development. Such an approach is coherent to Alonso (2011) whose critics of institutional theory allowed to derive several its drawbacks but still to confirm the central role of institutions in long-term economic growth; and Angeles (2011) concluding that "institutions have come to be seen as a major determinant of long-run economic development".

An important role in elimination of institutional traps belongs to mechanisms of control, which represent a set of instrumentally mediated stimulating or restricting reactions to an institution's failure to follow the prescribed behavior patterns, as well as to the means of their diagnostics and detection. Control mechanisms are both external and embedded within an institution. External control, e.g., by means of governmental supervision, is characterized by clear functional specialization of controlling bodies who, respectively, enact rules, monitor compliance and impose sanctions. The 
mechanism of external control is based on the formal fixation of the system of norms and rules and the subsequent provision of their implementation within power-subordinate relations. Practical realization of external control is based on social technologies that are, by their nature, an instrument of communicative interaction. Destructive social technologies assist to elimination of institutional traps' effects, since these technologies represent an instrument of external control and are designed to systemize efforts of a managing body to reframe an object to achieve the necessary result.

Mechanisms of internal control or self-control within institutional entities represent such a way to organize interaction between agents, in which each actor is both an object and a subject of control within the network structures of intra-institutional interaction. Just as external (formal) mechanisms of control, the internal ones also rely on a system of sanctions, the validity of which from the point of view of an individual can be higher, as well as the individual perception of the possibilities and consequences of their application. Thus, judgements, suggesting that mechanisms of control based on collective responsibility have the higher efficiency rather than the formal mechanisms, appear reasonable.

Development of the whole set of institutions as a component of socio-economic system is achieved by means of intermediaries' interactions within institutional environment with minimal amount of institutional restrictions. Institutional intermediaries are expected to perform a function of increasing the level of connectedness of socio-economic space by intensifying and facilitating the linkages between main agents of economic activity. The arguments in favor of the existence of institutional intermediaries boil down to the following:

- Proper informing in a situation of a deficit of relevant and reliable information about an institution that is reformed may greatly improve efficiency of managing the decision-making process in the institutional sphere. Otherwise, changes will be largely spontaneous, not based on proper justification, and decisions about changes will be made by economic actors on their own, that is not necessarily collinear to the interests of the authorities;

- Poor quality of information supplied to the process of institutions development administration undermines the effectiveness of plans and other prospective documents. Due to this, institutional intermediaries can be much demanded regarding the interest of public authorities, to some extent because they could bear expenses to organize planning the institutional dynamic and plans implementation; 
- Delegation of planning functions to the intermediaries will make it possible to avoid the significant changes in legislation, which are also laborintensive, especially when it comes to the fact that they may not be justified by other considerations and interests that go beyond the institutional agenda;

- A comprehensive assessment of the existing framework of institutional interaction within a system in terms of optimality, rationality and effectiveness, implemented by the authorities, may be both impracticable due to lack of proper competencies and biased in terms of possible involvement of the persons making assessment. The solution to this problem can be found in the use of institutional intermediaries.

Intermediaries presence is explained by heterogeneity of the institutional environment, which motivates to obtain quick benefits rather than to chase a long-term sustainable result. From the point of view of the market conditions, public regulation and of legislation updates, the most important reform is the one to combat bureaucracy and to get rid of unnecessary barriers. The present inconsistence between business practices and the activities of public authorities together with the absence of transparent rules of interaction create the risk of corruption and mediation, the latter being often illegal. Moreover, it can be concluded that authorities themselves create administrative barriers and, consequently, institutional traps. Thus, in fact, by the increase of stability, the state creates a strong factor of influence on social and economic development, dominantly negative by its nature because stability is achieved by means of institutional traps. Examples of ineffective governance are given in the paper of $\mathrm{S}$. Zhavoronkov, who illustrated negative effects generated by institutional traps on example of a flood in Krymsk district of Krasnodar region in 2012, which caused death of more than 170 people (Zhavoronkov, 2012).

As noted by Gasanov, Zhironkin, and Hellmer (2017), overcoming institutional traps requires the state to create the institutional foundations of economic policy, in which the technological modernization and innovative development of the industry will be linked to the imperative of social wellbeing growth. In this regard, it is the institution of mediation that can provide strategic benefits. Development agencies are among the most significant institutional intermediaries in the context of increasing the level of social and economic development. Their tasks and functions may differ due to the existence of unique characteristics of each territory, but the main goal of development agencies is still preserved: they are designed to eliminate management disfunctions that entail partial and inefficient use of the main economic actors' potential. 


\section{Institutional Reform}

The transition of the Russian economy and its regions to an innovation development path requires the creation of a network of sustainable institutions, which leads to the development of a methodology for institutional reform with special attention to the process of determining the factors of institutional stability. The object of reform is the socioeconomic space as an environment for institutional processes. In up-to-date conditions, the largest perspective is given to the network model of institutional structure, which assumes the appearance of meta-institutions with the use of cloud technologies, which should be greatly facilitated by development of an innovative information base in the region.

Notably, analysis of the Russian regions' empirical studies demonstrates the absence of a clear and well-developed model of institutional construction as a component of regional strategic policy, there is no full-fledged methodological tools and regulatory framework that establishes the procedural aspect of the reforms.

Institutional transformations should fit organically into economic activity and consider tendencies inherent in the institutional sphere. Among them is the growing dynamics of institutions development, following the transformation and expansion of the sphere of social relations, in which an increasing number of economic actors are involved. Given this background, the value of information, knowledge, intellectual and social capital that shape the basis of a knowledge economy is maximally increased, the full development of which depends on the proper functioning of the supporting institutions. The growing volumes of information flows generated in the institutional sphere determine the overall trend of institutions' reform and the emergence of a new framework of the socio-economic system with its virtual and network structures.

The growing intensity of competitive relations and the expansion of transnational companies' market role force institutions to adopt new features and characteristics inherent in their foreign counterparts and prototypes, since this is precisely the means to maintain their competitiveness at the proper level. This leads to the fact that under the influence of both stimulating and destructive factors, institutions attempting to tune up increase their level of sustainability but lose the ability to become strategically dynamic and highly differentiated in terms of functional and purposeful design structures with authentic functioning mechanisms.

It is necessary to note the emergence in the institutional environment of such a phenomenon as the hybridization of institutions. The 
latter describes the conditions in which institutions, similar in terms of structure, composition and scope, being combined produce the synergetic effect, and in which the combination leads to collapse. Thus, the equivalence of institutions in terms of their spatial morphological features within the same institutional environment may not lead to actual unification of institutions. In this case, hybridization describes only a hypothetical model of their interaction as a result of information flows synchronization and proper identification of actors' requests.

Contemporary conditions with their inherent transfrontency, high information mobility, increased power of an individual and growing influence of network structures dictate the need to revise the institutional agenda, as well as to develop a theoretical and methodological basis for institution building and reform, with a clear manifestation of the state and the society attitude towards this issue. A characteristic feature of modern institutions is the endogenous character of their formation, in contrast to the patterns of interaction of economic agents that are planted from the outside. At the same time, the multiplicity of institutions makes regional socioeconomic space very dense and competitive, which triggers mechanisms of generating and accumulating social and institutional capital, the rational use of which in practice ensures the main goal of the institutional environment to express and to represent individuals' interest, and to intermediate their interactions.

Similarly, the number of external and internal incentives for the modernization of institutions is also constantly increasing. They include different factors ranging from policy changes and fluctuations in the global market environment to technological innovations, local fashion surges, marginal ideas, and so on. At the same time, the traditional drivers of institutions' modernization are still relevant: education, the implementation of democratic rights and freedoms, growing social and economic differentiation, scientific and technological progress, crises or, on the contrary, periods of growth.

The features and trends observed in the institutional environment can be identified and systematized as follows:

- Growth of diversity of forms and attributes of social relations considering the exercise of interests of economic actor groups is happening both intensively and extensively that determines the next stage of the institutional sphere development. The intensive development path of institutional environment is indicated by the increasing degree of institutions' individualization that peaks of which introduce different anomalies like institutions serving private interests. The extensive 
development path determines the growing variety of institutions within the conditional boundaries of society, while the variety turns out to be nominal because of partially or significantly duplicated functions or scope of institutional clones.

- Consequential of the extensive growth of institutional diversity is the high level of their heterogeneity and polymorphism: along with formal and informal institutions, various intermediate and temporal structures arise, characterized by specific models of intra- and inter-institutional interactions, and of information flows and processing organization. The term of "localization" becomes less attributable to institutions in the light of metainstitutions emergence, that service the needs of actros within and beyond the given territory. The mentioned diversity and heterogeneity of institutions necessitate the use of non-standardized approaches to assessing the parameters of their functioning; the set of parameters should vary significantly.

- Institutional environment changes tend to speed up their pace: institutions are forced to increase their degree of adaptability to the environment by increasing the mobility of their resource base. Growing uncertainty increases the facilitating role of development institutions and increases demand for future-oriented research that enables drafting the road maps of social relations development within the key areas of stakeholder groups' interference, as well as deriving forecasts and plan estimates. The conditions of communication within the society are highly heterogenous which is rather normal given the extent of similarity and differentiation of stakeholder groups. Taken in greater detail, it is correct to state that noncontradictory interests also hierarchical that allows to classify those interests and provides a rational basis for their formalized comparison. Thus, full harmonization of interest can be probably the least likely, but the most favorable option. The 100-percent concord would eliminate the very need for institutions, at least as facilitators of interaction of differently motivated actors. The next level of development of the communication environment is an unanimity of interests with a notable degree of specialization that does not require actors to compromise to achieve their own goals of interaction. Subordination or mutual subordination of interests are themselves the form of communicative interaction that creates the ground for institutionalization: economic agents often realize that chasing their interests will only be successful if some third-party's interest will be maintained, thus need some mediation since the chain of interests may not be a closed loop of two participants. In the latter case the described situation characterizes 
communicative interactions associated with mutually overlapping interests when each actor will seek to establish contact.

- The transformation of economic conditions leads to a change in the preferences of consumers, and, therefore, imposes new demands on institutions whose activities are built on the assessment of market demands and requirements on the part of actors. This makes institutions not ready for rapid transformation to erode from the market. Adaptive institutions, in turn, face uneven generation of flows, which increases volatility their performance indicators.

- Massive interdependent transfer of social capital from one institution to another takes place because of institutional activity intensification and elimination of many conservative-style inert institutions. External environment dynamism and the increase of uncertainty level stimulate inflexible institutions to respond to changes of management practices and brings to the forefront the need to adapt changes in mechanisms to incorporate risk management tools.

Institutional reforms that do not consider features of the contemporary economic system, as well as internal and external development factors that can cause fluctuations of institutional environment, cannot ensure generation of sustainable institutions and lead to undesirable shifts in social, economic, cultural and other spheres. The study of institutional transformations today should be aimed at identifying the most successful practices in the regions and developing algorithms for their dissemination. Successful practices are intended to become the basis and empirical material for analyzing and identifying ways and means to improve the conditions for institutional reform. They can become a basis for developing models of institutional transformation in the Russian regions.

\section{Conclusion}

Currently there are many institutions in Russia that promote development and can support potential startups in priority sectors. These institutions are complex and sophisticated and are aimed at activating a new model of economic growth - the "green economy" (Rudneva, Pchelinceva, \& Gureva, 2017). Without proper institutional policy and administration, it is impossible to ensure the optimal path of development. The growth in quantities of positive institutional practices and successful experience in reforming institutions is can serve as an instrument of a social state development. Practical evidence shows that the increase of the level of socio-economic development of territories, as shown in Kookueva and 
Tsertseil (2017), does not lead to the development gap elimination, moreover, the gap between "rich" and "poor" regions growth up instead. However, if we proceed from the thesis that a social state is not a state with no "rich" and "poor" and the development level is "the same" everywhere, but rather is the state having just no "poor", then the adaptation of institutional experience, albeit in varying degrees, will increase the level of socio-economic development of all territories. Social justice is achieved in this case not so much by equal access to social goods as by social inclusion of various groups in the social security system, and by their involvement in development institutions. The policy implementation with this approach is aimed not at leveling out more, but at ensuring the rights, freedoms and dignified life of citizens. Social policy then should be differentiated since different social groups demand different forms of support. Promotion in the issue of social equality can be facilitated by the "model of inclusion" of citizens in the regional development institutions' activities.

Development institutions given the diversity and multi-purpose orientation can obtain significant prospects if organized according to the principles of meta-institutions construction. Their design and practical implementation is a strategic task and can be more successful if the methodology of institutional reform is applied. Thus, understanding the possible negative impact of both institutional traps and unstable institutions on the whole system of social relations and the harmonious development of the socioeconomic system increases the role of improving the institutional environment through reform.

\section{References}

Alonso, J. (2011). Colonisation, Institutions and Development: New Evidence. Journal of Development Studies, 47(7), 937-958. doi:https://doi.org/10.1080/00220388.2010.527948

Angeles, L. (2011). Institutions, Property Rights, and Economic Development in Historical Perspective. KYKLOS, 64(2), 157-177. doi:https://doi.org/10.1111/j.1467-6435.2011.00500.x

Caballero, G., \& Soto-Onate, D. (2015). The Diversity and Rapprochement of Theories of Institutional Change: Original Institutionalism and New Institutional Economics. Journal of Economic, 49(4), 947-977. doi:https://doi.org/10.1080/00213624.2015.1105021

Deroy, X., \& Clegg, S. (2015). Back in the USSR: Introducing Recursive Contingency Into Institutional Theory. Organization Studies, 36(1), 7390. doi:https://doi.org/10.1177/0170840614544556 
A Philosophical Approach of the Modernization Process of Russian Economy ...

Alexandra GRIGORIEVNA POLYAKOVA, et.al.

Dollar, D. (2016). Institutional quality and growth traps. Paper presented the Conference on Asia and the Middle-Income Trap, Beijing.

Draskovic, V., Popov, E., \& Peleckis, K. (2017). Modelling of Institutional Changes in Transition Countries the Gap Between the Theory and Practice. Montenegrin Journal of Economics, 13(1), 125-140.

Gasanov, M., Zhironkin, S., \& Hellmer, M. (2017). Identification of Institutional Traps of Wellbeing in Deindustrializing and Structural De-socializing Conditions. Paper presented at the WELLSO 2016 - III International Scientific Symposium on Lifelong Wellbeing in the World.

Kolmakov, V., \& Polyakova, A. (2017). Health sector performance under Private-Public Partnership. European Proceedings of Social and Behavioural Sciences, 26, 436-443.

doi:https://doi.org/10.15405/epsbs.2017.07.02.56

Kookueva, V. V., \& Tsertseil, J. S. (2017). Problems of Minimum salary in Russia. European Proceedings of Multidisciplinary Sciences, 1, 66-79. doi:https://doi.org/10.15405/epms.2017.06.8

Kremser, C. E. W. (2016). Economic Growth Theory and Philosophy of History The Theory of Institutional Change by Douglass C. North. Vierteljahrschrift für Sozial- und Wirtschaftsgeschichte, 103(1), 34-53.

Marshall, A. (1920). Principles of Economics. London: Macmillan.

Polterovich, V. M. (1999). Institutional traps and economic reforms.

Economics and Mathematical Methods, 35(2).

Rudneva, L., Pchelinceva, I., \& Gureva, M. (2017). Creating a Development Model of "Green" Economy. European Proceedings of Multidisciplinary Sciences, International Conference on Responsible Research and Innovation (RRI).(XXVI - RRI 2016), 286-294.

doi:https://doi.org/10.15405/epsbs.2017.07.02.37

Sultan, A., \& Washbrook, D. (2017). Introduction: Institutions and economic development in South Asia. Modern Asian Studies, 51(6), 1657-1667. doi:https://doi.org/10.1017/S0026749X17000099

Tridico, P. (2011). Institutions, Human Development And Economic Growth In Transition Economies. London: Palgrave Macmillan.

Williams, C., \& Horodnic, I. (2016). An institutional theory of the informal economy: some lessons from the United Kingdom. International Journal Of Social Economics, 43(7), 722-738.

Yanovskiy, K., \& Shulgin, S. (2008). Institutions, democracy and economic growth: 180-year development trial. Economic policy, 3, 57-75.

Yekimova, K. V., Savelyeva, I. P., \& Tsalo, I. M. (2016). Assessment of the Impact of the Changes in the Situation of the World Markets on the 
Regional Processes. Ekonomika regiona - Economy of Region, 12(3), 670683. doi:https://doi.org/10.17059/2016

Zhavoronkov, S. (2012). Political and economic results of July 2012.

Economic and political situation in Russia, 7, 5-7. 